Karolina Válová (D)

Universidade Carolina de Praga karolina.valova@ff.cuni.cz

\title{
Quatro coisas encontradas: análise espacial da casa no romance Para Sempre de Vergílio Ferreira
}

\section{Resumo:}

O artigo apresenta a análise espacial da casa no romance Para Sempre (1983) de Vergílio Ferreira, um dos maiores escritores existencialistas da literatura portuguesa. Paulo, o narrador autodiegético, está de regresso à casa amarela, à casa da sua infância. É o regresso definitivo que inicia a última fase da sua vida, o tempo que lhe falta até à morte. Deambulando pela casa, percorrendo corredores, subindo e descendo escadas, entrando em cada quarto, encontra um tempo imóvel que revela o seu passado, e o faz pensar sobre o futuro e os seus sonhos. Encontra também quatro coisas-símbolos (o violino, o chapéu de palha, o relógio e a estatueta de anjo) que funcionam como chaves. Com o apoio da obra filosófica A poética do espaço (La poétique de l'espace, 1957) de Gaston Bachelard constatamos que a casa amarela representa a vida de Paulo.

Palavras-chave: romance português do século XX, existencialismo, símbolo, casa, espaço

\section{Abstract: \\ Four Things Found: Spatial Analysis of the House in the Novel Para Sempre by Vergílio Ferreira}

The article presents the spatial analysis of the house in the novel Forever (Para Sempre, 1983) by Vergílio Ferreira, one of the greatest existentialist writers in Portuguese literature. Paulo, the self-digetic narrator, is returning to the yellow 
house, to the house of his childhood. It is the definitive return that begins the last phase of his life, the time it lacks until death. Wandering around the house, running down corridors, up and down stairs, entering each room, finds a stopped time, reveals his past again and thinks about his future and his dreams. There are also four symbol-things, the violin, the straw hat, the clock, and the angel figurine, that work as keys. With the support of Gaston Bachelard's philosophical work Poetics of Space (La poétique de l'espace, 1957), it is discovered that the yellow house represents the life of Paul.

Keywords: Portuguese novel of the $20^{\text {th }}$ century, existentialism, symbol, house, space

Vergílio Ferreira foi considerado um dos maiores autores existencialistas na literatura portuguesa. $O$ foco da sua extensa obra consiste em prosas fortemente influenciadas pela filosofia, passatempo de toda a vida do filólogo graduado. Rodrigues Paiva caracteriza a obra de Ferreira como

a obra plural cheia de significações simbólicas, de abstrações que podem representar uma memória ou o cosmos, o absoluto ou o relativo, um Eu, um outro e que, sobretudo, privilegia a Palavra, a Linguagem como elemento fundamental à criação de universos. É obra que constantemente questiona os seus próprios limites e possibilidades. (Paiva, 2007: 17-18)

O romance Para Sempre de 1983 pertence ao grupo de textos vergilianos ligados à temática da velhice, morte e sobretudo à instabilidade e fugacidade da vida humana, as quais em geral representam um estudo sofisticado do homem e do significado do seu ser. Entre outras prosas deste grupo temático, podemos nomear como exemplo Até ao Fim de 1987 ou Em Nome da Terra de 1990.

O romance Para Sempre inicia-se com as palavras "Para sempre. Aqui estou" e termina com palavras muito parecidas, praticamente iguais. No final, verificamos que a repetição de "para sempre" dá a noção de um círculo: o círculo da história, o círculo da vida. Esta locução "para sempre" é nota do narrador autodiegético, o Paulo, um homem velho que vivia há muitos anos na capital. Ele está de regresso à casa amarela, no campo fora do mundo civilizado. Está de regresso à casa 
abandonada por muitos anos, à casa mal cuidada, à casa da sua infância. Chega como recém reformado, sem amigos e sem membros da família. A sua mulher, Sandra, morreu há muitos anos atrás, e também não mantém contato com Xana, a sua filha adulta. Paulo sabe perfeitamente que é um regresso último, um regresso definitivo, que significa estar à espera da morte.

O romance descreve uma época curtíssima, apenas a tarde do dia da chegada, uma tarde ardente de Verão. A história termina com o pôr do sol. Passo a passo, Paulo visita todos os quartos; deambula pela casa, percorre corredores, sobe e desce as escadas, abre e fecha todas as portas e janelas. Revela, ou melhor, re-descobre a casa outra vez para si mesmo. Encontra vários móveis, e coisas deitadas no chão quase lixo, as quais pertenceram a ele ou aos vários membros da sua família. Lembra-se dos tempos passados, recapitula a vida. Neste vaguear pela casa, e ao tropeçar na "acumulação de trastres pelo chão" (Ferreira,1983: 22) Paulo tropeça também num tempo sem cronologia. Passa mais uma vez pela sua infância, adolescência e os seus amores, e tenta conformar-se com a realidade sombria. Em alguns momentos tenta mesmo imaginar e visualizar o seu próprio futuro. Tem consciência que a nova vida nesta casa representa um tipo de precursor da eternidade, que corresponde ao título do livro. "Dou a volta à casa toda, dou a volta à vida toda e é como se um desejo de a totalizar, a ser na mão. Ter a imagem visível de tudo quanto a construiu, rever-me nela para a levar comigo" (Ferreira, 1987: 43).

De acordo com Rodrigues de Paiva e o seu livro Vergílio Ferreira: Para sempre, romance-síntese e última fronteira de um território ficcional, a chegada de Paulo à aldeia bucólica e calma não é meramente uma reintegração num lugar conhecido desde a infância e adolescência, mas um retorno simbólico às raízes. Ele volta aos lugares dos quais foi expulso pela matrícula no processo educativo, pelo casamento e depois pelo emprego. No fim da vida, ele retorna não apenas à sua "primeira casa", mas também ao útero, aos braços aconchegantes da mãe. Vergílio Ferreira compara Paulo ao rei exilado, que depois do seu retorno deve assumir o governo. "A volta definitiva para casa, parte integrante e fundamental desse vasto sentimento cósmico em que se 
fundem tempo e espaço, a terra e o Homem, os limites e o sem-fim, a montanha e a Casa." (Paiva, 2007: 319)

Ao entrar na casa, silenciosa e vazia, Paulo abre todas as janelas de par em par para o horizonte. Observa o panorama com o fascínio da amplidão espacial, aberta à luz e à terra, chegando à linha do horizonte. Ao longe, a montanha sobe, citando o autor "ainda até à roxidão", e adiante "o sem-fim". Segundo Gavilanes Laso a montanha é um dos topos fundamentais da poética vergiliana juntamente com o caminho, a casa e a aldeia. As montanhas na prosa dele não são partes duma paisagem fantástica inventada, mas uma parte real duma região portuguesa, Serra da Estrela, com que o autor estava relacionado. Têm ainda uma função simbólica: "A montanha é também força maior do universo, dá ânimo e consegue aplacar a angústia sufocada do personagem." (Gavilanes Laso, 1989: 93)

O regresso de Paulo à casa amarela da infância é mais que o retorno às origens, a um cosmos ao qual pertence e de onde a vida o afastara em exílio. É sobretudo um regresso a si mesmo, à sua existência, o retorno a um ventre, a um seio materno metafórico. $\mathrm{O}$ retorno à casa do passado é um regresso ao próprio eu, que por sua vez, procura o conhecimento de si mesmo. Regressar a casa é também para Paulo retornar ao princípio da vida. A casa da infância registada na memória, a casa do ser na descoberta do mundo. Gaston Bachelard analisa e destaca o berço como símbolo no seu famoso livro $O$ espaço poético (La poétique de l'espace, 1957) ao afirmar que este funciona como uma pré-casa, como lugar de proteção e segurança: "sempre, em nossos devaneios, a casa é um grande berço". (Bachelard, 1974: 359).

A casa é, portanto, o local exclusivo para a história e a própria composição do romance é parcialmente adaptada à arquitetura interna da casa. A morada é re-descoberta por Paulo da mesma maneira que se manifesta a sua alma ao leitor. A ideia da construção da casa como a alma humana foi apresentada por Bachelard em $O$ espaço poético. Além de uma certa "harmonia" entre os ambos textos, outro traço comum é que Para sempre parece mais um poema em prosa do que uma narrativa comum. Bachelard afirma que as memórias do mundo exterior nunca são tão claras como as memórias da casa. No 
processo de recordação, segundo Bachelard, somos mais poetas do que historiadores.

Não apenas as nossas lembranças, mas também os nossos esquecimentos estão aí "alojados". Nosso inconsciente está "alojado". Nossa alma é uma morada. E quando nos lembramos das "casas", dos "aposentos", aprendemos a morar em nós mesmos. Vemos logo que as imagens da casa seguem nos dois sentidos: estão em nós assim como nós estamos nelas. (Bachelard, 1974: 355)

A casa de Paulo é uma casa de memórias. Durante a sua viagem através da casa movimenta-se por espaços seguros, como salas e quartos, para pontos de mistério e perigo, como a zona subterrânea, a cave. Em ambos os lugares se encontram vários objetos simbólicos.

Segundo Paiva, uma obra como Para Sempre pede muito mais interpretação do que análise, pois mostra-se francamente aberta a diferentes leituras. "Deseja explicações de múltiplas e amplíssimas metáforas artísticas. É uma obra que abrange a dimensão romanesca e poética ao mesmo, tudo de uma vez." (Paiva, 2007: 18)

O espaço da casa no romance Para Sempre é um espaço emocionado e emocionante, e a evocação que suscita permite a reinvenção das coisas. As coisas encontradas são laços que ligam Paulo às diversas épocas da sua vida. Objetos simbólicos representam os motivos principais e repetitivos do livro. Funcionam também como uma espécie de chave de acesso condicionado aos lugares memória. "Nesses espaços, os objetos funcionam como chaves de acesso condicionado aos lugares da memória. Um objeto gasto pelo uso pode ser um poema de saudade ou, por outras palavras, a presença de uma ausência." (Gavilanes Laso, 1989: 60). Neste livro são vários, como é o exemplo da máquina de costura da tia Luisa; a folha de vogais da Xana; a imagem da Virgem na parede; o baú de couro, etc. Nesta curta análise a que nos propomos, dedicar-nos-emos apenas a quatro dos objetos: o violino (representa a arte), o relógio de corda (simboliza o tempo), a estatueta do anjo com a asa quebrada (representa a fé em Deus) e o chapéu de palha com a fita azul (simboliza o amor). 


\section{O violino}

No primeiro andar entre uma estante quebrada e uma velha caixa de papelão, Paulo encontra um estojo de violino preto. A forma do estojo é, segundo o narrador, parecida a um caixão de bebé. Dentro revela um instrumento musical verdadeiro, cujo tamanho corresponde a três quartos. O pequeno violino pertencera-lhe nos tempos em que frequentava as aulas de música, lecionadas pelo padre da igreja local.

Paulo, após tantos anos, tenta tocar o violino no quarto abandonado. A música foi parte de si por muito tempo da sua vida. O tamanho do violino e caixão de bebé referem-se à sua infância, onde ocorreu a sua primeira experiência com a música e com a arte em geral. Para ele, a música expressava-se como um alívio durante uma infância árdua e sem amor. As tias que o educaram viviam uma vida devota e rigorosa. Durante o seu ensino musical conseguia, quanto mais não fosse, receber um tratamento digno, sem punições corporais e outras humilhações. Graças à música, Paulo melhorou de atitude relativamente às visitas à igreja forçadas pelas suas tias. Em público, tocou violino pela primeira vez nessa mesma igreja durante a missa. A música concedia-lhe uma aura de algo extraordinário. Segundo as suas palavras, para ele "foi uma descoberta de beleza" ou "foi quase uma revelação" (Ferreira, 1983: 129).

A descoberta do violino na casa velha é uma revelação semelhante. Antes de o encontrar, Paulo passa por um caminho iluminado. Uma parte do quarto é iluminada por um raio de sol que atravessa a janela aberta. Luz que parece quebrar o silêncio da casa, parece quebrar algum mau feitiço. Deparamo-nos com esta iluminação extraordinária e inesperada em cada encontro com os objetos simbólicos mencionados no início desta análise. É, portanto, uma iluminação da mémória, e também um aviso simples ao "milagre comum", durante o qual as coisas comuns de uso diário se tornam objetos mágicos e sagrados.

E é através dos estados cativantes do corpo e do espírito, da harmonia inesperada, que Paulo vivencia a presença da música, passamos ao conceito de música, respetivamente à arte em geral no romance Para sempre. A arte ressalta e ultrapassa o homem mortal. É uma atividade 
humana mais nobre. Como Ferreira explica no seu livro de ensaios chamado Espaço do Invisivel 1 de 1965: "a sensibilidade artística é o aviso mais marcante de que estamos no mundo". "sensibilidade [artística] é o sinal mais evidente da nossa presença no mundo". (Ferreira, 1990: 37)

Não obstante o processo de instalação e re-descobrimento na casa, esta acaba por se enquadrar num simbólico geral, pois significa o início. A série de atos de Paulo depois da mudança e da longa época de inabitação é lógica. Ele abre as portas e janelas como motivação da própria orientação no espaço. Ele necessita da luz do dia e de ar fresco. Por outro lado, podemos também observar todos os seus atos a nível símbólico. Podemos lê-los como pequenas epifanias. É Gavilanes Laso quem no seu livro Vergílio Ferreira. Espaço Simbólico e Metafisico fala sobre as epifanias no romance Para sempre. Paulo, durante a primeira entrada na casa encontra o tempo imóvel, que está à espera de alguém, que o desperte e o decifre. A crescente luminosidade solar torna tudo mais claro e nítido. Paulo triunfa sobre a escuridão, a vida volta à casa da mesma maneira que volta ao castelo enfeitiçado e hibernado nos contos de fadas.

\section{O relógio}

Bachelard afirma que o organismo da casa tem um tempo condensado. Esta formulação quase poética pode ser entendida na medida em que o espaço é um reservatório da memória na sequência de gerações.

Paulo encontra um relógio de corda na cozinha. Em geral o relógio que faz tique-taque é sinal de casa habitada, é um sinal de existência de vida local. No entanto, este relógio não funciona. Parou há muitos anos. Todavia, Paulo conseque dar corda ao relógio e devolver o tempo à casa outra vez. Por outro lado, os movimentos do pêndulo avisam visivelmente o período limitado que tem para a reconstrução da sua vida através do seu monólogo interior. Ele tem a noção que o lhe tempo escapa, tal como the escapa a palavra ideal. Ele busca a palavra assim. A palavra total, palavra absoluta; a palavra do fim, condensada e inviolável que podia dar sentido à vida. 


\section{A estatueta do anjo}

No quinto capítulo da Poética do Espaço Bachelard destaca que a casa é um corpo de imagens que dão às pessoas uma confiança ou uma ilusão de permanência. Acima de tudo, a casa é apresentada como um ser vertical que se opõe a um ser central. A verticalidade é assegurada pela polaridade da cave e do sótão. A sua teoria foi formulada segundo uma parte do livro L'homme à la découvert de son âme, 1963 dum psicanalista C. G. Jung que analisou os medos presentes na casa.

A cave é um lugar sem janelas em que está escuro durante o dia inteiro, e por onde o tempo passa de outra maneira. Segundo Bachelard, é sobretudo a escuridão da casa, que está envolvida em forças subterrâneas. Na definição muito simples bachelardiana, a cave representa a inconsciência. Em Para sempre a cave tem os sintomas de uma zona proibida muito parecida à paisagem da morte, parecida ao tártaro. Descer a cave e depois subir as escadas é para o protagonista um processo comparável com a morte e reanimação, ou melhor, a ressurreição. Para Paulo tem um efeito terapêutico do ponto de vista da culpa reprimida pela falta de intimidade no relacionamento com Sandra, e pela falta de amor em relação à filha. Na cave ele pensa sobre os antepassados, sobre as sombras deles, que, como ele, deixaram lá os seus vestígios. E na cave encontra a estatueta de um anjo que tem uma asa quebrada. Mais uma vez, o raio de sol consegue atravessar a porta da entrada e iluminar por um momento a estatueta. Paulo sobe para a casa com a estatueta nas mãos. Encontra algumas semelhanças entre o anjo mutilado e a sua infância mutilada. $O$ anjo é também um símbolo da fé perdida. Paulo revela que nunca tinha acreditado em Deus, no entanto, a ausência de Deus na sua vida é uma experiência dolorosa.

\section{O chapéu de palha}

Paulo encontra o chapéu de palha no primeiro andar da casa. Segundo a teoria da verticalidade é um lugar de sonhos, de alta consciência. O chapéu é uma forma de tesouro, ou melhor, de um prémio, pois Paulo deve superar os obstáculos quase como se se tratassem de rituais 
para o obter. Passa por um corredor escuro cheio de calor húmido e, após atravessar a porta dupla, luta com as persianas bloqueadas. Através da janela libertada chega o ar fresco e outra vez a luz do dia, a luz do sol. Além disso, o chapéu não se encontra no chão como se se tratasse de outro traste, mas está pendurado num gancho. Pertencia a Sandra e foi provavelmente a própria, a esposa, e o maior amor de Paulo, quem o pendurou. O encontro do chapéu liberta as memórias e as saudades de Sandra. Esta morreu alguns anos atrás, devido a uma doença incurável e durante a estadia na cidade. Pensar na sua esposa foi um processo muito doloroso para Paulo. Posteriormente à sua morte, ele nem conseguiu mais falar sobre ela.

A fita azul do chapéu está associada ao "azul celestial no cabelo". A cor azul é um dos atributos de Sandra. Funciona como um tipo de aura divina, que se assemelha à Virgem Maria, mas também como o sintoma de uma certa frieza emocional. Sandra nunca se referiu aos seus sentimentos, nem ao seu amor. A relação entre eles como vida de casados foi bastante complicada, sem harmonia e sem grandes paixões. Paulo procura palavras adequadas para várias situações até ao fim da sua vida. Para ele a sua maior luta interna tratou-se da comunicação com Sandra. Entre eles os sentimentos mais profundos eram expressos sem palavras. No entanto, durante a noite de núpcias, Paulo diz a Sandra "amo-te", mas não em voz alta. Di-lo em voz baixa, no "ninho" seguro, envolto, escondido debaixo de um cobertor, fazendo lembrar uma casa pequena dentro de uma outra. Sandra responde o mesmo, repete essas mesmas duas palavras. A palavra que sai da boca dela está muito próxima, mas ainda não foi essa, a palavra perfeita, final, imortal, única e absoluta.

\section{Referências bibliográficas}

BACHELARD, G. (1974), A poética do espaço, Abril Cultural, São Paulo. FERREIRA, V. (1983), Para Sempre, Bertrand Editora, Lisboa.

FERREIRA, V. (1990), "Vida, arte” em: Ferreira, V., Espaço do Invisível 1, Bertrand Editora, Lisboa. 
GODINHO, H. (1982), Estudos sobre Vergílio Ferreira, Imprensa Nacional-Casa da Moeda, Lisboa.

GAVILANES LASO, J. L. (1989), Vergílio Ferreira. Espaço Simbólico e Metafisico, Publicações Dom Quixote, Lisboa.

PAIVA, J. R. (2007), Vergílio Ferreira: Para sempre, romance-síntese e última fronteira de um território ficcional, Editora Universitária, Recife. 